\title{
Heroin and Cocaine Dependence and the Risk of Accidental Non-Fatal Drug Overdose
}

\author{
Sandro Galea, MD, DrPH \\ Ari Nandi, MPH \\ Phillip O. Coffin, MIA \\ Melissa Tracy, MPH \\ Tinka Markham Piper, MPH \\ Danielle Ompad, $\mathrm{PhD}$ \\ David Vlahov, $\mathrm{PhD}$
}

\begin{abstract}
The relation between illicit drug dependence and the likelihood of drug overdose is unclear. We recruited 1,066 habitual drug users for this analysis through street-based outreach in New York City. In this sample, $99.3 \%$ of respondents used heroin in the past year and $87.1 \%$ of respondents used cocaine; $819(77.5 \%)$ heroin users and $735(79.2 \%)$ cocaine users were severely dependent on either drug, respectively. In multivariable models, among heroin users, persons who were severely heroin dependent were less likely $(\mathrm{OR}=0.6 ; 95 \% \mathrm{CI}=0.4-0.9)$ to have overdosed on any drug in the past year; among cocaine users, those who were severely cocaine dependent were more likely $(\mathrm{OR}=1.6 ; 95 \% \mathrm{CI}=1.0-2.6)$ to have overdosed in the past year. The relation between illicit drug dependence and risk of overdose may vary for different patterns of drug dependence. These observations suggest that overdose prevention interventions, perhaps even those specifically targeting opiate overdose, may be more efficiently directed at individuals exhibiting cocaine dependence. [Article copies available for a fee from The Haworth Document Delivery Service: 1-800-HAWORTH. E-mail address: <docdelivery@haworthpress.com> Website: <http://www.HaworthPress. com> (C) 2006 by The Haworth Press, Inc. All rights reserved.]
\end{abstract}

KEYWORDS. Drug dependence, overdose, heroin, cocaine

\section{INTRODUCTION}

Non-fatal drug overdoses are common among illicit drug users; ${ }^{1-3}$ the annual prevalence of non-fatal overdose among illicit drug users has been estimated to be $10-30 \%$. $^{3-6}$ Non-fatal drug overdoses are associated with considerable morbidity including indirect (e.g., broken limbs

Sandro Galea and Melissa Tracy are affiliated with the Department of Epidemiology, University of Michigan School of Public Health, Ann Arbor, MI. Sandro Galea, Ari Nandi, Phillip O. Coffin, Melissa Tracy, Tinka Markham Piper, Danielle Ompad, and David Vlahov are affiliated with the Center for Urban Epidemiologic Studies, New York Academy of Medicine, New York, NY. Sandro Galea and David Vlahov are also affiliated with the Department of Epidemiology, Columbia University Mailman School of Public Health, New York, NY.

Address correspondence to: Sandro Galea, MD, DrPH, Center for Social Epidemiology and Population Health, Department of Epidemiology, University of Michigan School of Public Health, 1214 South University, Ann Arbor, MI 48104 (E-mail: sgalea@umich.edu).

This work was funded by grants DA-06534, DA-12801-S1, and DA-017642 from the National Institutes of Health.

Journal of Addictive Diseases, Vol. 25(3) 2006

Available online at http://jad.haworthpress.com

(C) 2006 by The Haworth Press, Inc. All rights reserved. doi:10.1300/J069v25n03_10 
or head injuries, burns, assaults) and direct (e.g., peripheral neuropathy, vomiting, chest infections, pneumonia, seizure or cardiac arrhythmia) morbidity. ${ }^{3}$ Persons with a history of non-fatal overdose are more likely to experience subsequent potentially fatal overdoses. For example, the median number of lifetime drug overdoses among those who have experienced an overdose ranges from 2-3.1,4 Extant research has identified the following factors associated with the increased likelihood of non-fatal drug overdose: age, ${ }^{6-8}$ duration of use, 1,5 frequency of use,, 45 route of administration, ${ }^{5,6}$ HIV status, ${ }^{5}$ alcohol use, ${ }^{1,6}$ and concomitant illicit drug use. . $^{1,4,7,9}$

Studies of non-fatal drug overdose among heroin users have shown that $48-55 \%$ of users are likely to be drug-dependent. 6,7 Toxicological findings from two studies of heroin-related deaths have suggested that $80-85 \%$ of fatal cases were dependent on heroin. ${ }^{10,11}$ However, relatively few studies have assessed the role of drug dependence in determining non-fatal drug overdose, $, 4,7$ and the extant literature is conflicting. Some research has shown that drug users who overdose have more symptoms of drug dependence than those who do not. ${ }^{1,6,7}$ For example, a study of 218 heroin users in Adelaide, Australia found that each additional point on the Severity of Dependence Scale (SDS; indicating higher levels of dependence) increased the odds of ever having overdosed by $12 \% .^{7}$ Conversely, other work has suggested that there is no relation between dependence on illicit drugs and the likelihood of experiencing a non-fatal overdose. ${ }^{4,12}$ For example, two studies of injection drug users from the UK found no difference in mean SDS scores between those who overdosed in the past year and those who did not. $4,12 \mathrm{We}$ are not aware of any work that has considered and contrasted the relationship between heroin and cocaine dependence and the likelihood of non-fatal overdose.

Recognizing that the identification of risk factors for non-fatal overdose could inform interventions that may mitigate overdose-related morbidity and mortality we assessed the relations between past-year heroin and cocaine dependence and non-fatal overdose in the past year in a sample of street-recruited drug users.

\section{METHODS}

\section{Participants and Procedures}

Participants were recruited by trained outreach workers in Central Harlem and the South Bronx in NYC from November 2001 through May 2004. Eligibility requirements included being eighteen years of age or older and having used heroin, crack, or cocaine at least once in the two months prior to the interview. Structured in-person interviews were conducted in English or Spanish by trained interviewers. The Institutional Review Board at the New York Academy of Medicine approved the study and all study subjects provided oral consent at the time of the interview.

\section{Measures}

Respondents were asked about demographic characteristics, including sex, race/ethnicity, age, educational attainment, marital status, and whether they were currently homeless. We asked respondents about their drug use behaviors, including drugs they had used in the past year, their injector status, the length of their heroin using career, the length of their cocaine using career, their overall drug use frequency in the past 2 months, and whether they had used tranquilizers or benzodiazepines in the prior year. For the purposes of these analyses, respondents reporting heroin use during the past year were considered heroin users and respondents reporting cocaine use during the past year were considered cocaine users. Based on a review of the literature and instruments used in studies in Adelaide, Australia ${ }^{13}$ and San Francisco, CA, USA, ${ }^{14}$ overdose was defined as "someone who collapses, has blue skin color, convulsions, difficulty breathing, loses consciousness, cannot be woken up, or has a heart attack or dies while using drugs." We asked respondents if they had ever overdosed during their lifetime; those who had overdosed were asked how many times they had overdosed in the past six months, in the past year, and in their lifetime.

We assessed heroin and cocaine dependence using the SDS. ${ }^{15}$ The SDS is an easily administered scale that can be used to measure the degree of psychological dependence experienced 
by users of different types of illicit drugs in different settings. ${ }^{15}$ The SDS has been demonstrated statistically to be a valid and reliable measure of current heroin and cocaine dependence. ${ }^{15,16}$ The SDS consists of five items: (1) Did you think your use of [named drug] was out of control? (2) Did the prospect of missing a fix (or dose) or not chasing make you anxious or worried? (3) Did you worry about your use of [named drug]? (4) Did you wish you could stop? (5) How difficult did you find it to stop, or go without [named drug]? The five items of the SDS are scored on a four-point scale (for items 1-4: $0=$ never/almost never, $1=$ sometimes, $2=$ often, $3=$ always/nearly always; for item 5: $0=$ not difficult, 1 = quite difficult, 2 = very difficult, 3 =impossible). A total SDS score is obtained by adding the scores of all items (range 0 -15) with higher total scores indicating higher levels of dependence. A test of the internal consistency of the scale among five samples demonstrated Cronbach alpha values between 0.80 and 0.90 and correlation levels between total scores and factor scores greater than $0.99 .{ }^{15}$ The SDS can be adapted to cover different types of drugs by modifying the reference to the named drug and can assess experiences over different timeframes. In these analyses, we assessed heroin and cocaine dependence in the past year. There is no standard diagnostic criterion for the SDS and cut-off points need to be determined independently for different drugs. ${ }^{17}$ A study reporting on the psychometric properties of the SDS in samples of heroin users showed that total SDS scores greater than or equal to seven were generally indicative of severe heroin dependence. ${ }^{6,7,15}$ Consistent with these findings, we considered heroin users scoring greater than or equal to seven on the SDS as severely dependent on heroin. In a study of recent cocaine users, Receiver Operating Characteristic (ROC) analysis comparing the SDS against the Composite International Diagnostic Interview (CIDI), a valid and reliable instrument for the diagnosis of dependence according to the Diagnostic and Statistical Manual of Mental Disorders-Fourth Edition (DSM-IV), produced an area under the curve value of 0.86 and showed that a total SDS score of greater than or equal to three discriminated best between the presence and absence of a DSM-IV diagnosis of cocaine dependence (sensitivity of $63 \%$, specificity of $93 \%$ ). ${ }^{17} \mathrm{In}$ these analyses, we considered past-year cocaine users scoring greater than or equal to three on the SDS to be severely dependent on cocaine.

\section{Statistical Analyses}

We calculated the prevalence of past-year non-fatal drug overdose among heroin and cocaine users, mean heroin and cocaine SDS scores, and the prevalence of heroin and cocaine users severely dependent on either drug respectively. The prevalence of past-year overdose within categories of heroin and cocaine SDS scores was determined. We developed separate multivariable models predicting pastyear overdose among heroin and cocaine users. Variables that were significantly associated with past-year overdose $(\mathrm{p}<0.05)$ were included in the final multivariable models. Restricting the sample to respondents who had used both heroin and cocaine during the past year we assessed the proportion of respondents who were severely dependent on heroin and cocaine, on heroin only, on cocaine only, and on neither drug. We compared the prevalence of overdose during the past year in each of these four groups using chi-square testing.

\section{RESULTS}

The demographic characteristics of the 1066 habitual drug users interviewed in this study are presented in Table 1. Among 1059 persons who used heroin during the past year, 178 (16.8\%) reported at least one non-fatal overdose in that time; among 928 persons who used cocaine during the past year, $158(17.0 \%)$ reported at least one overdose. The mean heroin SDS score among heroin users was $9.7(\mathrm{SD}=4.3)$ and the mean cocaine SDS score among cocaine users was $7.7(\mathrm{SD}=5.0)$. Eight hundred nineteen (819) heroin users $(77.5 \%)$ scored greater than or equal to seven on the SDS and were considered severely dependent on heroin; 735 (79.2\%) cocaine users scored greater than or equal to three on the SDS and were considered severely dependent on cocaine. The prevalence of past year overdose within categories of heroin and cocaine dependence are presented in Figures 1 and 2 , respectively. 
TABLE 1. Overdose, dependence, demographic, and drug use characteristics of heroin and cocaine drug user samples, New York City.

\begin{tabular}{|c|c|c|c|c|}
\hline \multirow[t]{2}{*}{ Characteristics } & \multicolumn{2}{|c|}{$\begin{array}{l}\text { Heroin Users } \\
(\mathrm{N}=1059)\end{array}$} & \multicolumn{2}{|c|}{$\begin{array}{l}\text { Cocaine Users } \\
(\mathrm{N}=928)\end{array}$} \\
\hline & $\mathbf{N}$ & $\%$ & $\mathbf{N}$ & $\%$ \\
\hline Past-year overdose & 178 & 16.8 & 158 & 17.0 \\
\hline \multicolumn{5}{|l|}{ Dependence } \\
\hline Mean SDS score (SD; range) & \multicolumn{2}{|c|}{$9.7(4.3 ; 0-15)$} & \multicolumn{2}{|c|}{$7.7(5.0 ; 0-15)$} \\
\hline \multicolumn{5}{|l|}{ Dependence categories } \\
\hline $0-2$ & 88 & 8.3 & 193 & 20.8 \\
\hline $3-6$ & 150 & 14.2 & 200 & 21.6 \\
\hline $7-10$ & 255 & 24.1 & 187 & 20.2 \\
\hline $11-15$ & 564 & 53.4 & 348 & 37.5 \\
\hline \multicolumn{5}{|l|}{ Demographics } \\
\hline \multicolumn{5}{|l|}{ Sex } \\
\hline Female & 263 & 25.1 & 210 & 22.9 \\
\hline Male & 786 & 74.9 & 707 & 77.1 \\
\hline \multicolumn{5}{|l|}{ Race/Ethnicity** } \\
\hline Black & 238 & 22.5 & 252 & 27.2 \\
\hline Hispanic & 682 & 64.5 & 556 & 60.0 \\
\hline White/other & 137 & 13.0 & 119 & 12.8 \\
\hline \multicolumn{5}{|l|}{ Age } \\
\hline 35 and older & 653 & 61.7 & 568 & 61.2 \\
\hline $18-34$ & 406 & 38.3 & 360 & 38.8 \\
\hline \multicolumn{5}{|l|}{ Educational attainment } \\
\hline Less than high school & 536 & 50.8 & 457 & 49.5 \\
\hline $\begin{array}{l}\text { High school or equivalent } \\
\text { and higher }\end{array}$ & 519 & 49.2 & 467 & 50.5 \\
\hline \multicolumn{5}{|l|}{ Marital Status } \\
\hline Never married & 668 & 63.1 & 600 & 64.7 \\
\hline Married & 139 & 13.1 & 122 & 13.2 \\
\hline Divorced/widowed/separated & 251 & 23.7 & 205 & 22.1 \\
\hline \multicolumn{5}{|l|}{ Currently homeless } \\
\hline No & 569 & 53.8 & 480 & 51.8 \\
\hline Yes & 489 & 46.2 & 447 & 48.2 \\
\hline \multicolumn{5}{|l|}{ Drug use behaviors } \\
\hline \multicolumn{5}{|l|}{ Injector status } \\
\hline Never injected & 107 & 10.2 & 127 & 13.9 \\
\hline Former injector & 253 & 24.0 & 212 & 23.1 \\
\hline Current injector & 694 & 65.8 & 578 & 63.0 \\
\hline \multicolumn{5}{|l|}{ Length of heroin using career* } \\
\hline$<17$ years & 512 & 49.6 & 435 & 51.2 \\
\hline$\geq 17$ years & 520 & 50.4 & 414 & 48.8 \\
\hline \multicolumn{5}{|l|}{ Length of cocaine using career* } \\
\hline$<20$ years & 499 & 47.9 & 438 & 47.8 \\
\hline$\geq 20$ years & 542 & 52.1 & 478 & 52.2 \\
\hline \multicolumn{5}{|l|}{$\begin{array}{l}\text { Overall drug use frequency past } 2 \\
\text { months }\end{array}$} \\
\hline$<$ Daily & 379 & 36.0 & 360 & 39.0 \\
\hline Daily & 675 & 64.0 & 563 & 61.0 \\
\hline \multicolumn{5}{|l|}{$\begin{array}{l}\text { Used tranquilizers, } \\
\text { benzodiazepines, or } \\
\text { barbiturates in the past year }\end{array}$} \\
\hline No & 809 & 76.4 & 710 & 76.5 \\
\hline Yes & 250 & 23.6 & 218 & 23.5 \\
\hline
\end{tabular}

*Length of drug using career dichotomized at median value for each drug **Sample was recruited from Harlem and the South Bronx, neighborhoods with high concentrations of Black and Hispanic individuals.
FIGURE 1. Prevalence of past year overdose within categories of heroin dependence, New York City heroin users $(\mathrm{N}=1,059)$.

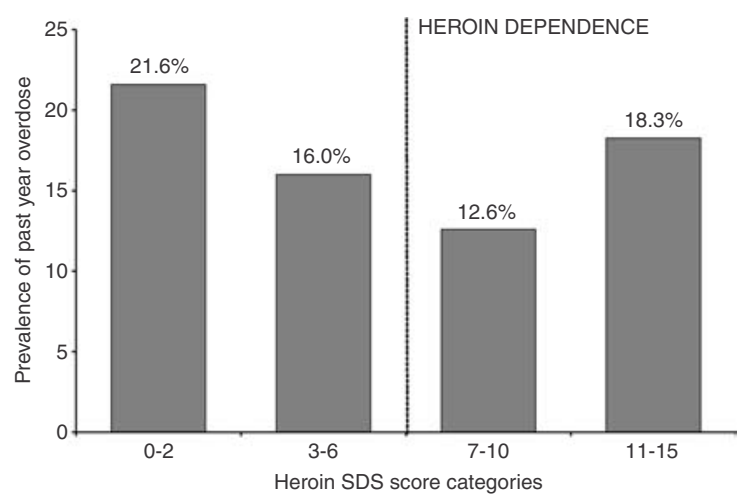

Heroin dependence assessed using the SDS; persons scoring 7 or more on the SDS (i.e., persons to the right on the dashed line in the figure above) were considered severely heroin dependent.

FIGURE 2. Prevalence of past year overdose within categories of cocaine dependence, New York City cocaine users $(\mathrm{N}=928)$.

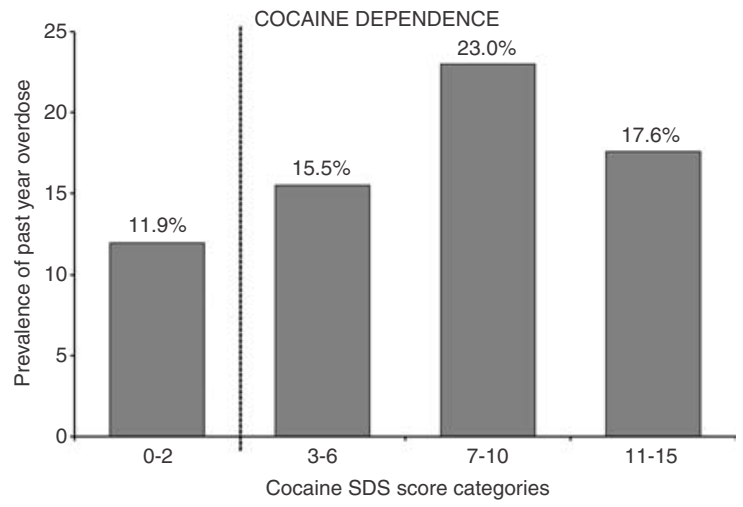

Cocaine dependence assessed using the SDS; persons scoring 3 or more on the SDS (i.e., persons to the right on the dashed line in the figure above) were considered severely cocaine dependent.

The results of a multivariable model predicting past-year overdose among heroin users are presented in Table 2. Persons who were severely dependent on heroin were less likely $(\mathrm{OR}=0.6 ; 95 \% \mathrm{CI}=0.4-0.9)$ to have overdosed in the past year. Higher educational attainment $(\mathrm{OR}=1.9$; 95\% CI $=1.3-2.6)$, current homelessness $(\mathrm{OR}=1.7 ; 95 \% \mathrm{CI}=1.2-2.5)$, being a current injector $(\mathrm{OR}=2.2 ; 95 \% \mathrm{CI}=1.1-4.7)$, and the use of tranquilizers or benzodiazepines $(\mathrm{OR}=1.9 ; 95 \% \mathrm{CI}=1.3-2.7)$ also predicted past-year drug overdose. Alcohol use in the 
TABLE 2. Multivariable model predicting past-year overdose among past-year heroin users ( $N=$ 1,059).

\begin{tabular}{|c|c|c|c|c|}
\hline \multirow[t]{2}{*}{ Characteristics } & \multicolumn{2}{|c|}{ Unadjusted } & \multicolumn{2}{|c|}{ Adjusted } \\
\hline & $\begin{array}{l}\text { Odds } \\
\text { Ratio }\end{array}$ & $\begin{array}{c}95 \% \\
\mathrm{Cl}\end{array}$ & $\begin{array}{l}\text { Odds } \\
\text { Ratio }\end{array}$ & $\begin{array}{c}95 \% \\
\mathrm{Cl}\end{array}$ \\
\hline \multicolumn{5}{|l|}{ Dependence } \\
\hline \multicolumn{5}{|l|}{ Heroin SDS score } \\
\hline 0-6 (not severely dependent) & 1.0 & - & 1.0 & - \\
\hline 7-15 (severely dependent) & 0.9 & $0.6-1.3$ & 0.6 & $0.4-0.9$ \\
\hline \multicolumn{5}{|l|}{ Demographics } \\
\hline \multicolumn{5}{|l|}{ Age } \\
\hline$\geq 35$ & 1.0 & - & 1.0 & - \\
\hline $18-34$ & 1.6 & $1.2-2.3$ & 1.3 & $0.9-2.1$ \\
\hline \multicolumn{5}{|l|}{ Educational attainment } \\
\hline Less than high school & 1.0 & - & 1.0 & - \\
\hline $\begin{array}{l}\text { High school or equivalent or } \\
\text { higher }\end{array}$ & 1.7 & $1.2-2.4$ & 1.9 & $1.3-2.6$ \\
\hline \multicolumn{5}{|l|}{ Currently homeless } \\
\hline No & 1.0 & - & 1.0 & - \\
\hline Yes & 1.9 & $1.4-2.7$ & 1.7 & $1.2-2.5$ \\
\hline \multicolumn{5}{|l|}{ Drug use behaviors } \\
\hline \multicolumn{5}{|l|}{ Injector status } \\
\hline Never injected & 1.0 & - & 1.0 & - \\
\hline Former injector & 1.2 & $0.5-2.5$ & 1.2 & $0.5-2.7$ \\
\hline Current injector & 2.5 & $1.3-4.9$ & 2.2 & $1.1-4.7$ \\
\hline \multicolumn{5}{|l|}{ Length of heroin using career } \\
\hline$<17$ years & 1.0 & - & 1.0 & - \\
\hline$\geq 17$ years & 0.6 & $0.5-0.9$ & 0.8 & $0.5-1.2$ \\
\hline \multicolumn{5}{|l|}{$\begin{array}{l}\text { Overall drug use frequency past } \\
2 \text { months }\end{array}$} \\
\hline$<$ Daily & 1.0 & - & 1.0 & - \\
\hline Daily & 1.6 & $1.1-2.2$ & 1.4 & $0.9-2.1$ \\
\hline \multicolumn{5}{|l|}{$\begin{array}{l}\text { Used tranquilizers, } \\
\text { benzodiazepines, or barbiturates } \\
\text { in the past year }\end{array}$} \\
\hline No & 1.0 & - & 1.0 & - \\
\hline Yes & 2.3 & $1.6-3.2$ & 1.9 & $1.3-2.7$ \\
\hline
\end{tabular}

past year was not associated with overdose risk among heroin users $(\mathrm{p}=0.114)$ and was thus not included in the multivariable model.

In a multivariable model among cocaine users (Table 3), persons who were severely dependent on cocaine were more likely $(\mathrm{OR}=1.6$; $95 \% \mathrm{CI}=1.0-2.6)$ to have overdosed in the past year. Higher educational attainment $(\mathrm{OR}=1.8$; 95\% CI $=1.3-2.6)$ and current homelessness $(\mathrm{OR}=1.6 ; 95 \% \mathrm{CI}=1.1-2.3)$ predicted pastyear overdose while greater overall frequency of drug use in the past two months $(\mathrm{OR}=1.6$;
TABLE 3. Multivariable model predicting past-year overdose among past-year cocaine users ( $\mathrm{N}=$ 928).

\begin{tabular}{lcccc}
\hline Characteristics & \multicolumn{2}{c}{ Unadjusted } & \multicolumn{2}{c}{ Adjusted } \\
& Odds & $95 \%$ & Odds & $95 \%$ \\
& Ratio & Cl & Ratio & Cl \\
\hline
\end{tabular}

Dependence

Cocaine SDS score

0-2 (not severely dependent) $1.0 \quad-\quad 1.0 \quad-$

3-15 (severely dependent) $\quad 1.7 \quad 1.0-2.7 \quad 1.6 \quad 1.0-2.6$

Demographics

Age

$\geq 35$

18-34

$\begin{array}{llll}1.0 & - & 1.0 & -\end{array}$

Educational attainment

Less than high school

High school or equivalent

or higher

Currently homeless

No

Yes

$\begin{array}{llll}1.8 & 1.3-2.6 & 1.5 & 0.9-2.4\end{array}$

$1.0 \quad-1.0$

$1.5 \quad 1.1-2.1 \quad 1.8 \quad 1.3-2.6$

rug use behaviors

Injector status

Never injected

Former injector

Current injector

$1.0 \quad-\quad 1.0 \quad-$

$1.8 \quad 1.3-2.5 \quad 1.6 \quad 1.1-2.3$

Length of cocaine using career

$<20$ years

$\geq 20$ years

$1.0 \quad-\quad 1.0=$

$1.3 \quad 0.7-2.8 \quad 1.1 \quad 0.5-2.4$

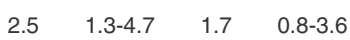

$1.0 \quad-\quad 1.0 \quad-$

$\begin{array}{llll}0.6 & 0.4-0.8 & 0.8 & 0.5-1.3\end{array}$

Overall drug use frequency past 2

months

$<$ Daily

Daily

Used heroin past year

No

Yes

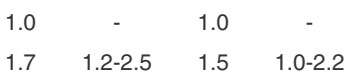

$1.7 \quad 1.2-2.5 \quad 1.5 \quad 1.0-2.2$

$1.0 \quad-\quad 1.0$ -

$2.1 \quad 1.1-4.1 \quad 1.1 \quad 0.5-2.4$

$95 \% \mathrm{CI}=1.0-2.3$ ) was marginally associated with overdose. Alcohol use in the past year was not associated with risk of overdose among cocaine users $(\mathrm{p}=0.389)$ and was not included as a covariate in the multivariable model.

Among 925 respondents who had used both heroin and cocaine in the past year (Table 4), $532(57.5 \%)$ were severely dependent on both heroin and cocaine, $178(19.2 \%)$ on heroin only, $125(13.5 \%)$ on cocaine only, and 90 $(9.7 \%)$ were not severely dependent on either drug. The prevalence of past-year overdose in each of these four groups was $18.1 \%, 14.6 \%$, $24.0 \%$, and $11.1 \%$, respectively $(\mathrm{p}=0.062)$. 
TABLE 4. Prevalence of severe dependence among persons who used both heroin and cocaine in the past year $(\mathrm{N}=925) .{ }^{*}$

\begin{tabular}{lrccc}
\hline Severely dependent on... & N & $\%$ & $\begin{array}{c}\text { N } \\
\text { overdose }\end{array}$ & $\begin{array}{c}\% \\
\text { overdose }\end{array}$ \\
\hline Both heroin and cocaine & 532 & 57.5 & 96 & 18.1 \\
Heroin only & 178 & 19.2 & 26 & 14.6 \\
Cocaine only & 125 & 13.5 & 30 & 24.0 \\
Neither heroin nor cocaine & 90 & 9.7 & 10 & 11.1 \\
\hline
\end{tabular}

${ }^{*}$ Chi-square $p$-value for contingency table 0.062 .

\section{DISCUSSION}

In a cross-sectional study of habitual drug users recruited through storefront sites and mobile outreach clinics in New York City, we found that $16.8 \%$ of respondents who used heroin during the past year and $17.0 \%$ of respondents who used cocaine during the past year experienced at least one overdose in that time. $77.5 \%$ of heroin users and $79.2 \%$ of cocaine users were severely dependent on either drug respectively. Among heroin users, persons who were severely dependent were less likely to have overdosed in the past year. In contrast, among cocaine users, persons who were severely dependent were more likely to have overdosed in the past year. Among respondents who used both drugs, persons who were dependent on cocaine only had the highest prevalence of overdose in the past-year, followed by those who were severely dependent on both drugs, and then by those severely dependent only on heroin.

We found that heroin users who were severely dependent on heroin were about half as likely to have overdosed in the past year compared to heroin users not dependent on heroin. In contrast to our findings, three studies have shown that heroin users who are more dependent on heroin, as measured by the SDS, are more likely to experience an overdose. ${ }^{1,6,7}$ However, we explicitly limited our analyses to overdose and dependence during the past year while in this previously published work, timeframe for dependence was not specified suggesting that the results may not reflect the natural history of drug use (i.e., long-term heroin users who recently cut down on their consumption may have still been considered dependent on heroin).
Heroin dependence may protect against overdose because dependent users may have more stable patterns of drug use; stable patterns of drug use in turn may confer increased levels of tolerance leaving non-dependent heroin users at a relatively greater risk of overdose. While little work has been conducted to show that stable patterns of drug use protect against overdose, a growing body of work shows the converse, that less stable and more sporadic patterns of drug use are associated with an increased likelihood of experiencing an overdose. ${ }^{10,18}$ For example, overdoses are more common after periods of abstinence or sporadic use, such as following release from prison ${ }^{10,19-21}$ or participation in drug treatment programs $8,22,23$ when tolerance levels are presumably lowered. Other studies provide conflicting evidence about the relation between frequency of use and risk of overdose. Brugal and colleagues similarly found that the risk of non-fatal overdose among heroin users decreased as the frequency of use increased. 5 Two studies that performed hair analyses on samples taken from heroin overdose decedents showed that fatal overdose cases exhibit hair morphine concentrations substantially lower than those of active users ${ }^{18,24}$ suggesting that fatal heroin overdose cases had less chronic heroin intake in the months preceding death than active street users. However, other work ${ }^{4}$ found that greater frequency of drug use was associated with higher risk of overdose. In our study we showed that heroin dependence was associated with lower risk of overdose independent of drug use frequency suggesting that behavior that is particular to dependence may be the critical protective factor.

In contrast to our findings for heroin dependence, cocaine users severely dependent on cocaine were more than one-and-a-half times as likely to have overdosed in the past year compared to cocaine users not severely dependent on cocaine. In one of the few studies to assess the relation between cocaine dependence and overdose, Ferri, Dunn, Gossop, and Laranjeira ${ }^{25}$ found that higher SDS scores, indicating greater levels of cocaine dependence, were associated with more frequent adverse reactions to cocaine among a sample of long-term users in Sao Paulo, Brazil. ${ }^{25}$ These findings are consistent with the clinical observation that patients with 
more severe cocaine dependence are more likely to present impaired control over their use of cocaine. ${ }^{25}$

Of note, almost the entire sample had used both heroin (99.3\%) and cocaine (87.1\%) in the past year. Furthermore, we did not specify which drug caused respondents' overdoses, i.e., thus those dependent on cocaine may have overdosed on cocaine, heroin, other drugs, or a combination. In a prior study, we found that nearly all accidental drug overdose deaths in New York City were due to opiates or cocaine, that three-fifths were due to a combination of cocaine, opiates, and alcohol, and that these multi-drug deaths accounted for most of the variation in fatality rates, i.e., multi-drug deaths may be particularly sensitive to outside influences. ${ }^{26} \mathrm{We}$ concluded that interventions to reduce overdose death should address the use of these drugs in combination. Our current findings, that among poly-drug users those with cocaine dependence are most at risk for an overdose, further suggest that overdose prevention interventions consider targeting individuals exhibiting cocaine dependence.

We also found that two demographic characteristics, higher educational attainment and current homelessness, predicted drug overdose among both heroin and cocaine users. We expected higher educational attainment to be associated with a reduced rather than increased risk of overdose; research designed to carefully explore this issue may further shed light on the socio-cultural determinants of overdose. While a high percentage of overdoses occur in a private home setting, ${ }^{7,11}$ other studies, ${ }^{8,27}$ as well as ours, show that being homeless is associated with the increased likelihood of experiencing an overdose. A recent study by Dietze et al. used a case-crossover design to demonstrate a threeto four-fold increase in the risk of heroin overdose among respondents who reported shifting from a private to public setting for drug use. ${ }^{28}$ Furthermore, homeless drug users may lack a stable social environment for drug use, causing them to engage in riskier drug use practices that increase the likelihood of overdose.

Two drug use characteristics predicted overdose among heroin users in our study, the use of tranquilizers or benzodiazepines and being a current injector. Our findings corroborate those of previous epidemiologic studies that have shown that concomitant drug use, particularly the use of nervous system depressants along with illicit drugs, is associated with the likelihood of drug overdose. ${ }^{1,2,7,10,12}$ However, these results must be interpreted with caution, as illicit drug users may take tranquilizers in response to adverse drug responses. Future research should determine if the relation between polydrug use and overdose is explained by the interaction of illicit drugs with central nervous system depressants or if the observed association reflects the consumption of tranquilizers and other depressants after an overdose. In our study, heroin users who were currently injecting were more than twice as likely to have experienced an overdose during the past year compared to heroin users who never injected. These results concur with previous work demonstrating that injecting is associated with a higher risk of overdose. ${ }^{3,6}$ In our sample the majority of participants had used alcohol in the past year (77.5\% of heroin users, $81.8 \%$ of cocaine users). However, although alcohol use has been associated with overdose risk in prior studies, ${ }^{1,6}$ no relation between past-year alcohol use and past-year overdose was demonstrated in this sample among either heroin or cocaine users. This may be a particular characteristic of this sample in this particular context. Further research is needed to elucidate the role alcohol may play in mediating the risk for overdose among heroin and cocaine users.

There were several limitations to this study. First, the cross-sectional nature of our study, which asked about drug overdose and drug dependence during the past year, prevented the establishment of temporality between drug dependence and the occurrence of an overdose. A longitudinal assessment is necessary to ensure that dependence symptomatology preceded the occurrence of an overdose. Second, we did not specify the type of drug overdose. Therefore, it is possible that respondents considered cocaine dependent in our study experienced an overdose caused by another drug, creating a complicated association between cocaine dependence and overdose. Because polydrug use is common among habitual drug users future studies may use clinical series and toxicological reports to identify the particular drug associated with an overdose. Third, we relied on self-report for our measures of drug use and drug de- 
pendence. While it is possible that this method of data collection resulted in inaccurate estimates of drug use and dependence, previous research has shown high validity in self-report assessments among drug users recruited in non-clinical settings. ${ }^{29-32}$ Fourth, the prevalence of cocaine use and cocaine overdose may be unusually high in New York City, limiting the generalizability of these findings to regions with similarly high rates of cocaine use. Fifth, information was not collected on alcohol abuse or dependence; this information may have provided a more complete picture of the relations between alcohol use and overdose risk.

Finally, we used targeted sampling techniques aimed at select neighborhoods to recruit a sample of habitual drug users from the population of drug users in New York City. Thus, the generalization of our results to other cities or populations must be made with caution.

With caveats considered, this study provides early evidence that the relation between illicit drug dependence and the likelihood of overdose may vary for different drugs. Our observations, combined with other analyses of drug overdose mortality data from New York City, ${ }^{33}$ suggest that interventions that aim to minimize overdose, perhaps even those specifically targeting opiate overdose, need to pay particular attention to those who are dependent on cocaine.

\section{REFERENCES}

1. Darke S, Ross J, Hall W. Overdose among heroin users in Sydney, Australia: I. Prevalence and correlates of non-fatal overdose. Addiction. 1996; 91:405-411.

2. Sergeev B, Karpets A, Sarang A, Tikhonov M. Prevalence and circumstances of opiate overdose among injection drug users in the Russian Federation. J Urban Health. 2003; 80:212-219.

3. Warner-Smith M, Darke S, Day C. Morbidity associated with non-fatal heroin overdose. Addiction. 2002; 97:963-967.

4. Bennett GA, Higgins DS. Accidental overdose among injecting drug users in Dorset, UK. Addiction. 1999; 94:1179-1190.

5. Brugal MT, Barrio G, De La Fuente L, Regidor E, Royuela L, Suelves JM. Factors associated with nonfatal heroin overdose: assessing the effect of frequency and route of heroin administration. Addiction. 2002; 97:319-327.
6. Gossop M, Griffiths P, Powis B, Williamson S, Strang J. Frequency of non-fatal heroin overdose: survey of heroin users recruited in non-clinical settings. BMJ. 1996; 313:402.

7. McGregor C, Drake S, Ali R, Christie P. Experience of non-fatal overdose among heroin users in Adelaide, Australia: circumstances and risk perceptions. Addiction. 1998; 93:701-711.

8. Seal KH, Kral AH, Gee L, Moore LD, Bluthenthal RN, Lorvick J, Edlin BR. Predictors and prevention of nonfatal overdose among street-recruited injection heroin users in the San Francisco Bay Area, 1998-1999. Am J Public Health. 2001; 91:1842-1846.

9. Ochoa KC, Hahn JA, Seal KH, Moss AR. Overdosing among young injection drug users in San Francisco. Addict Behav. 2001; 26(3):453-460.

10. Darke S, Ross J, Zador D, Sunjic S. Heroin-related deaths in New South Wales, Australia: 1992-1996. Drug Alcohol Depend. 2000; 60:141-150.

11. Zador D, Sunjic S, Darke S. Heroin-related deaths in New South Wales, 1999: toxicological findings and circumstances. Med J Aust. 1996; 163:204-207.

12. Powis B, Strang J, Griffiths P, Taylor C, Williamson S, Fountain J, Gossop M. Self-reported overdose among injecting drug users in London: extent and nature of the problem. Addiction. 1999; 94:471-478.

13. McGregor C, Darke S, Ali R, Christie P. Experience of non-fatal overdose among heroin users in Adelaide, Australia: circumstances and risk perceptions. Addiction. 1998;93(5):701-711.

14. Ochoa KC, Hahn JA, Seal KH, Moss AR. Overdosing among young injection drug users in San Francisco. Addict Behav. 2001;26(3):453-460.

15. Gossop M, Drake S, Griffiths P, Hando J, Powis B, Hall W, Strang J. The Severity of Dependence Scale (SDS): psychometric properties of the SDS in English and Australian samples of heroin, cocaine and amphetamine users. Addiction. 1995; 90:607-614.

16. Gossop M, Best D, Marsden J, Strang J. Test-retest reliability of the Severity of Dependence Scale. Addiction. 1997; 92:353

17. Kaye S, Darke S. Determining a diagnostic cutoff on the Severity of Dependence Scale (SDS) for cocaine dependence. Addiction. 2002; 97:727-731.

18. Darke S, Hall W, Kaye S, Ross J, Duflou J. Hair morphine concentrations of fatal heroin overdose cases and living heroin users. Addiction. 2002; 97:977-984.

19. Seaman SR, Brettle RP, Gore SM. Mortality from overdose among injecting drug users recently released from prison: database linkage study. BMJ. 1998; 316:426-428.

20. Bird SM, Hutchinson SJ. Male drugs-related deaths in the fortnight after release from prison: Scotland, 1996-99. Addiction. 2003; 98:185-190.

21. Seymour A, Oliver JS, Black M. Drug-related deaths among recently released prisoners in the Strathclyde Region of Scotland. J Forensic Sci. 2000;45(3): 649-654. 
22. Strang J, McCambridge J, Best D, Beswick T, Bearn J, Rees S, Gossop M. Loss of tolerance and overdose mortality after inpatient opiate detoxification: follow up study. BMJ. 2003; 326:959-960.

23. Jones R, Gruer L, Gilchrist G, Seymour A, Black M, Oliver J. Recent contact with health and social services by drug misusers in Glasgow who died of a fatal overdose in 1999. Addiction. 2002; 97:1517-1522.

24. Tagliaro F, De Battisti Z, Smith FP, Marigo M. Death from heroin overdose: findings from hair analysis. The Lancet. 1998; 351:1923-1925.

25. Ferri CP, Dunn J, Gossop M, Laranjeira R. Factors associated with adverse reactions to cocaine among a sample of long-term, high-dose users in Sao Paulo, Brazil. Addict Behav. 2004; 29:365-374.

26. Coffin PO, Galea S, Ahern J, Leon AC, Vlahov D, Tardiff K. Opiates, cocaine and alcohol combinations in drug overdose deaths in New York City, 1990-1998. Addiction. 2003; 98:739-747.

27. O’Driscoll PT, McGough J, Hagan H, Theide H, Critchlow C, Alexander R. Predictors of accidental fatal drug overdose among a cohort of injection drug users. Am J Public Health. 2001; 91:984-987.
28. Dietze P, Jolley D, Fry C, Bammer G. Transient changes in behaviour lead to heroin overdose: results from a case-crossover study of non-fatal overdose. Addiction. 2005 May;100(5):636-642.

29. Darke S. Self-report among injecting drug users: a review. Drug Alcohol Depend. 1998; 51:253-263.

30. Dowling-Guyer S, Johnson ME, Fisher DG, Anderson M, Watters JK, Williams M, Kotranski L, Booth R, Rhodes F, Weatherby N, Estrada AL, Fleming D, Deren S. Reliability of drug users' self-reported HIV risk behaviors and validity of self-reported recent drug use. Assessment. 1994; 1:383-392.

31. Nyamathi A, Leake B, Longshore D, Gelberg L. Reliability of homeless women's reports: concordance between hair assay and self report of cocaine use. Nurs Res. 2001; 50:165-171.

32. Watters J, Needle R, Brown B, Weatherby N, Booth R, Williams M. The self-reporting of cocaine use [letter]. JAMA. 1992; 268:2374-2375.

33. Coffin PO, Galea S, Ahern J, Leon AC, Vlahov D, Tardiff K. Opiates, cocaine and alcohol combinations in drug overdose deaths in New York City, 1990-1998. Addiction. 2003; 98:739-747.

\section{Get Articles FAST with the Haworth Document Delivery Service and Rightslink ${ }^{\circledR}$}

To request single articles from Haworth, visit

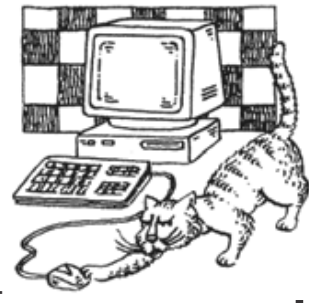
www.HaworthPress.com/journals/dds.asp. You can order single articles here directly from Haworth or through Rightslink $^{\circledR}$. We have over 40,000 articles ready for immediate delivery, and you can find articles by title, by author name, by keyword, and more!

R I G H T S L I N K > 